\title{
Smart Bicycles in an Urban Area: Evaluation of a Pilot Scheme in London
}

Robert B. Noland and Muhammad M. Ishaque, Imperial College, London

\section{Abstract}

Automated or smart bicycle systems are seen as a way to enhance mobility and provide a convenient access and egress mode for public transport. This article summarizes an evaluation of a pilot system that was introduced in the London Borough of Hammersmith and Fulham in August 2004. Underground and commuter rail stations, as well as a heavily-used bus network, serve this densely populated area of London. A survey of users was conducted and data were collected from actual use of the system. Analysis of these data provided some insights into the capabilities of these types of systems to enhance existing public transport services. In particular, it was found that the potential of the system lies primarily with the leisure and recreational market and with providing links to public transport stations. The pilot included "sponsored" nonpaying users who tended to use the system more for commuting and utilitarian trips.

\section{Introduction}

Bicycles, now recognized as an integral component of a good public transport system, are a convenient access mode to many rail and metro systems. Use of bicycles increases the ability to draw customers from a wider area. Bicycles are also frequently allowed onto public transport systems, providing egress from destina- 
tion stations and enhancing customer mobility. Bicycles can also reduce the need for extensive access and egress service from stations, lessen congestion on existing bus routes, and reduce the need for car parking at stations. The key drawback is the ability to take bicycles onto public transport during peak travel periods when passenger congestion is present. An alternative is to provide bicycle rental facilities at stations, but labor costs associated with this can be high.

A new approach is to automate the rental process. This article evaluates OYBike, an automated (or smart) bicycle pilot scheme that was introduced in the London Borough of Hammersmith and Fulham (LBHF) in August 2004. This program was envisioned as potentially providing enhanced mobility options for local residences and for those employed within the borough. It was also seen as both an alternative to public transport, mainly by shifting some trips from the bus network, and as a complementary mode, for both access and egress from Underground and rail stations.

Implementation of smart bicycle systems is becoming increasingly common. For example, one of the more successful programs, the Call-a-Bike system in Germany (http://www.callabike-interaktiv.de), is operated by the German National Railway. This system extends existing bicycle rentals that have long been offered at rail sta-

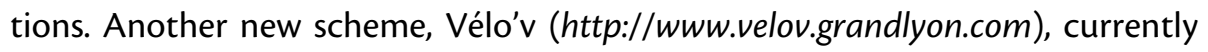
running in Lyon, France, is heavily subsidized by the City and is geared at providing mobility within the city, similar to the objectives of the pilot program evaluated here.

Evaluation of the London-based scheme sought to analyze the travel patterns of users (e.g., what type of trips were being taken with the bicycles and how they interacted with the public transport system). The analysis also evaluated the market potential of expanding the scheme into other parts of the Greater London area. Actual usage data for one full year of operation were analyzed. An analysis of scheme costs and maintenance issues was also conducted.

DeMaio and Gifford (2004) previously provided an overview of smart bicycle systems in existence in 2004. OYBike was not yet in use when their review was conducted. Their research evaluated the efficacy of such a system in the United States, as most existing systems are in Europe. Our aim is to provide some quantitative evidence on how these systems actually work within the context of a densely populated urban area with a high-quality but overcrowded public transport system. 
As in many other places around the world, London transportation planners are seeking ways to reduce car use. Public transport has played an important role in London, where bus usage has increased by more than 31 percent since 2000 and various initiatives have substantially increased bus service (Transport for London 2004a). London boroughs are required by the Mayor's Transport Strategy to develop plans for increasing bicycle use (Greater London Authority 2001). About 2.5 percent of worktrips involve a bicycle, and usage is reported to have increased substantially since 2000. Counts of Thames River bicycle crossings in Central London have increased by 40 percent in five years (Transport for London 2004b). Thus, there is significant interest in finding ways to increase and accommodate bicycle usage.

The article begins with an overview of the technical details of the OYBike system (more details are available at www.oybike.com). We then describe the pilot scheme as implemented. Actual usage data and responses from user surveys are discussed. Results of the analysis and conclusions are also presented.

\section{OYBike Technology}

OYBike is an innovative approach to bicycle rental. The system, a network of street-based rental stations, operates from 6:30 AM to 6:30 PM. Bicycles can be rented using a mobile phone and returned at later hours.

Bicycles are secured to automated locks placed on bicycle stands with cables (see Figures 1 and 2) and attached to Sheffield or "hitching post" style bicycle racks. Each bicycle stand is equipped with a specially-developed electronic lock with a keyboard and LCD display. The lock holds the cable secure until the bicycle is rented and released. Users are given unique PIN codes through their mobile phones via text messaging to both release and return the bicycle. The duration of each hire (from pick-up to drop-off) is monitored by the system, and the user's account is billed and debited accordingly.

An initial registration fee of $€ 10$ (about US $\$ 17$ ) is charged and the hire costs start at $30 p$ ( $\$ 0.51)$ for 15 minutes. The maximum charge for a full-day rental is $€ 8(\$ 13.60)$ (for each 24-hour period). Fares are set so that short trips of 30 minutes or less are relatively cheap, but charges increase thereafter. The flat rate for a full-day rental is relatively inexpensive per hour of use compared to shorter time periods. Rentals of more than 30 minutes and up to 3 hours garner the highest hourly rate, at $£ 2 /$ hour ( $\$ 3.40$ /hour). Thus, the current charging regime favors either very short- 




Figure 1. OYBike Locking Station

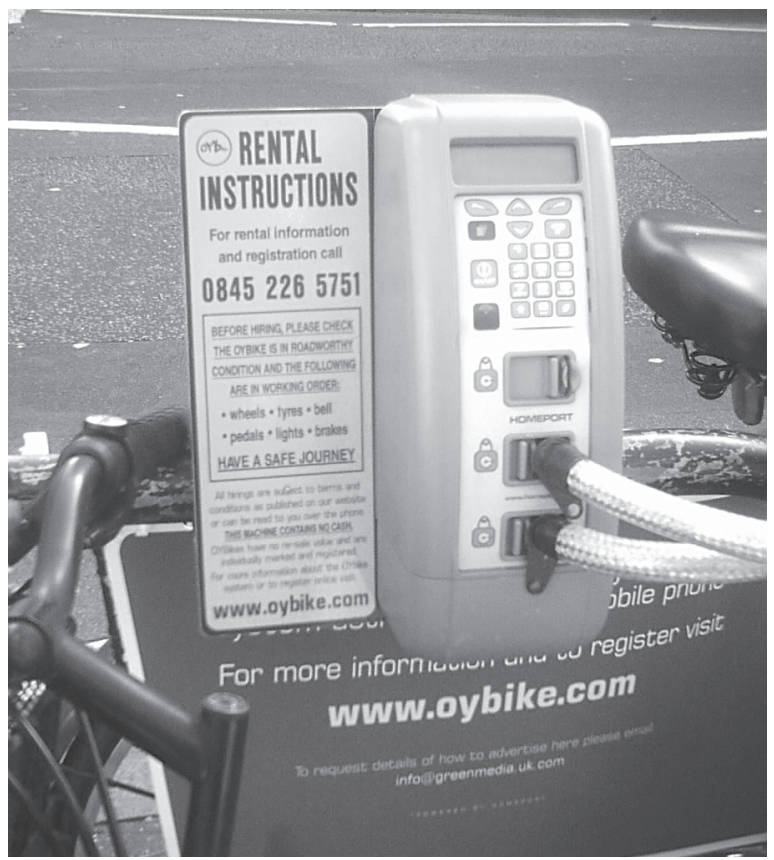

Figure 2. Close-Up of Automated Locking System 
term or full-day usage. Table 1 outlines the rate schedule as of December 2005.

\section{Table 1. OYBike Price Schedule}

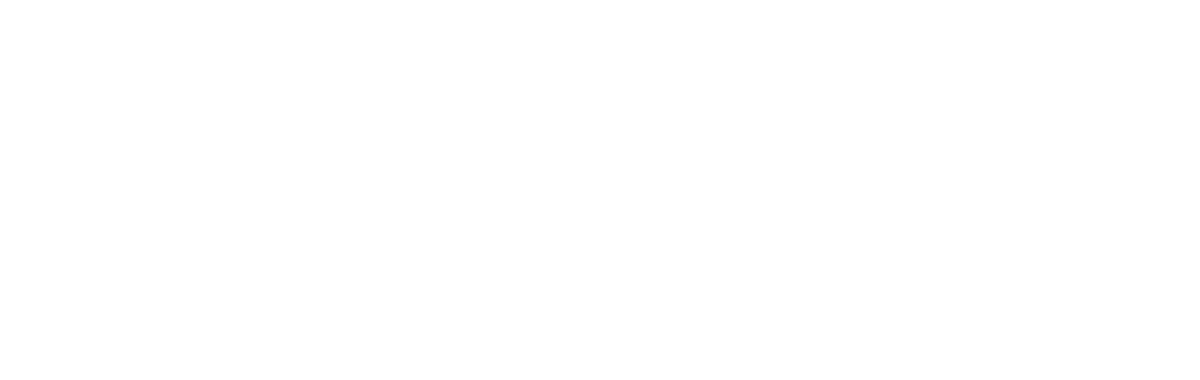

Rental stations are established at key originating and destination travel zones (e.g., Underground stations, public buildings, car parks). About 25 rental stations were operating in LBHF during 2005.

The bicycles, equipped with a basket to allow users to carry small items, have been designed for durability and visibility-each bicycle is bright yellow. They also have an area for advertising space, which is an additional source of revenue for the system. The bicycles' hydraulic drive system minimizes maintenance problems associated with traditional chain-based drives.

\section{The OYBike Pilot}

The pilot scheme took place in LBHF, which is located to the west of Central London outside of the congestion-charging zone. LBHF is a densely populated area, primarily residential but with various employment centers scattered throughout the borough. Among the employers in the area is the British Broadcasting Company (headquarters and studios), located in the north of the borough. The central area is around the Hammersmith Underground multimodal station. The south side of the borough is bordered by the Thames River and is the location of the London Wetlands Centre, the primary visitor and tourist attraction within the borough. The local authority was approached to work with the project due to the compactness of the borough, high levels of cycling activity, and a relatively welldeveloped bicycle network with good bicycle parking facilities (more than 1,000 bicycle racks for public use). 
The borough, traversed by the Piccadilly, District, Hammersmith and City, and Central Underground lines, has a dense bus network and several commuter rail stations. As in most central areas of London, public transport is the primary mode of transport. Car use is also heavy, partly due to the entry to the M4 motorway, a major route to the west and to Heathrow Airport. Household car ownership in the borough stands at 51 percent (Ball and Brooks 2004).

The OYBike system was made available for public use on August 22, 2004; the first registration for the service took place on August 23. This research evaluation encompasses one full year of usage, with data collected until August 21, 2005. The beginning of the pilot in late August hampered the early start-up of the system, as weather conditions were less favorable for bicycle use as the autumn months approached. About 25 locking stations were scattered throughout the borough, with 70 bicycles available in total.

In addition to public usage, OYBike arranged for several companies and the local authority to be "sponsored users" of the system. Sponsored users were given free access to the bicycles. This evaluation examines both public and sponsored use.

\section{Survey of Existing Customers}

In early September 2005, one year after the start of the pilot, an on-line survey of existing customers was conducted. Registered users who responded to an email request to fill out a web-based questionnaire were offered a usage credit of $£ 10$. Of 209 registered and sponsored customers who were emailed, 46 full questionnaires were used for the analysis. Given the size of this response rate, one should bear in mind that this sample is potentially biased. Users most satisfied with the system would be more likely to respond, given that the incentive to complete the questionnaire was a $£ 10$ credit for future use of OYBike. Clearly, those dissatisfied with the system or with no intention to use it again would be less likely to respond to this type of incentive.

\section{Demographics}

Of the 46 respondents, 50 percent resided in the borough and 35 percent lived elsewhere in London. The remainder lived outside of London or overseas. Most respondents also work in London (63\%), while a smaller fraction work in LBHF (22\%). A small fraction was unemployed or retired. 
Thirty-three percent of the respondents were women and 67 percent were men. Of those living in LBHF, 44 percent were women and 56 percent were men. Of those living outside the borough, 84 percent were men. The largest age group was those of age 26-35 years, accounting for 61 percent of the sample.

\section{Reported Travel Behavior}

Very few respondents (7\%) normally travel to work or school using a car, as shown in Table 2. Forty-three percent of respondents commute via public transport, mainly the Underground. A large percent normally commute on a bicycle (30\%). This should not be too surprising, as we would expect those who currently use bicycles to be more interested in at least testing out the system.

\section{Table 2. How Do You Normally Travel to Work or School?}

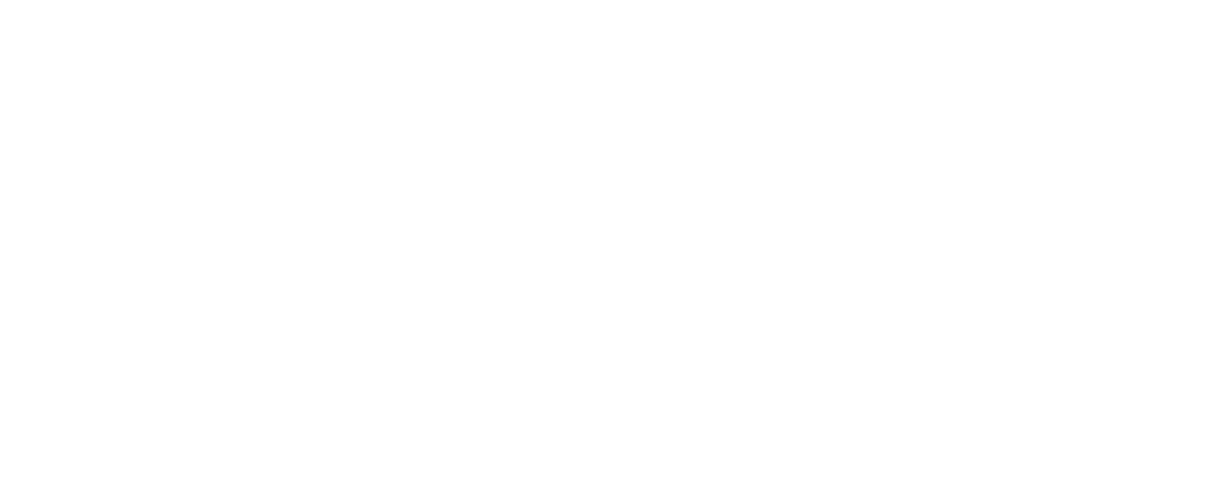

The stated purposes of trips using OYBike are shown in Table 3. Leisure and recreational trips account for the major uses. Commuting and other utilitarian trips represent about one-quarter of all trip purposes. Those living outside of $L B H F$ have a slightly higher share of recreational trips (74\%), compared to 63 percent for local residents, suggesting that visitors to the borough are more likely to use the bicycles for recreation.

Despite this high reported recreational use of the bicycles, many respondents noted that the trips they took are substituting for public transport trips (Table 4). This accounts for 34 percent (coming from buses and the Underground). A large share (21\%) would have previously walked, and these users likely reduced their travel times. Twenty-three percent would not have previously made the 
trip. These may be recreational trips, but clearly this shows a benefit in allowing increased mobility for these users. Only 6 percent shifted from using a car. This is a surprisingly large number given the type of trips that would be substituted, and shows potential environmental benefits from the system.

Table 3. When You Use OYBike, the Purpose of Your Travel Is Mainly...?

Table 4. The Journey(s) That You Take with OYBike Were Previously Taken By...?

Of particular interest from a transport policy perspective is whether the bicycles are used in combination with other modes of travel (Table 5). Most users, especially those living in LBHF, walk to the OYBike locking station $(61 \%$ in total and $78 \%$ of LBHF residents). Only 37 percent of non-LBHF residents walked to the locking station. Twenty-six percent used rail or the Underground previously. While this is relatively small, it does suggest some ability for the bicycles to be an egress 
Table 5. Do You Use a Bus, Rail, or the Underground as Part of Your Journey with OYBike?

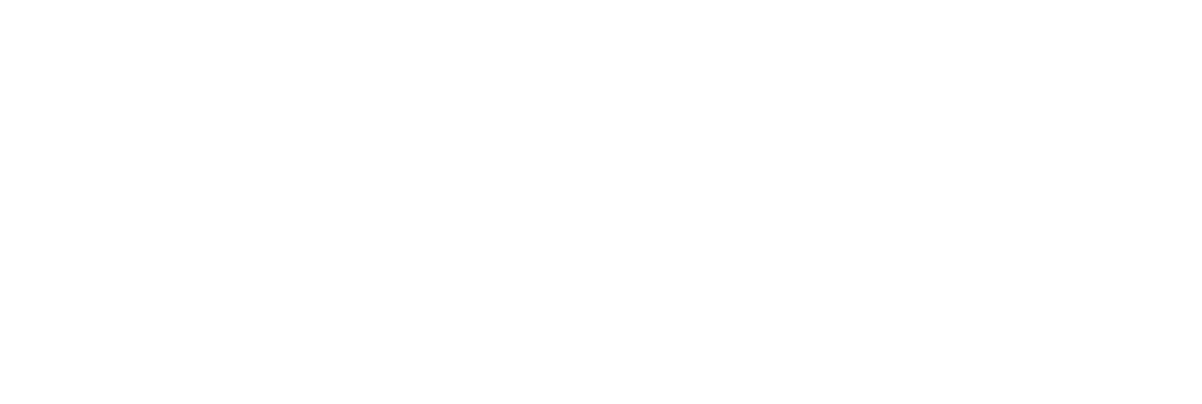

mode away from the station. Likewise, a small percent (13\%) use OYBike to access the Underground. Analysis of usage data revealed that 40 percent of all paid trips began or terminated at locking stations located outside Underground stations. The convenience of OYBike as an egress mode is further highlighted by examining why users do not use their own bicycles. Of 24 respondents reporting that they own a bicycle, one-third use the OYBike service because of its convenience in conjunction with the Underground.

\section{Perceptions of the OYBike System}

In trying to understand system usage, it is helpful to learn about respondents' experiences using OYBike and, in particular, any specific problems that they may have encountered. A series of questions investigated these issues.

Table 6 presents results from questions regarding issues and weaknesses in the current design of the system. In particular, the need to make a phone call and the difficulty of the locking system were of concern to many respondents. More than one-third also cited the overall maintenance of the bicycles. Surprisingly, cost was not an issue for the majority of respondents.

The locking system was also highlighted in responses to the question about problems with the system (Table 7). Twenty-six percent of respondents reported having problems with the locking system. Only 28 percent reported no faults with the bikes or the system as a whole, suggesting that maintenance issues need to be addressed. The gearing system, in particular, seems to be a source of problems.

Despite these problems, 78 percent of respondents were either satisfied or very satisfied with their OYBike travel experience. Only 11 percent reported levels of dissatisfaction, implying that the system is quite positive, although as previously 
Table 6. From Your Experience of Using OYBike, Is There Anything You Are Concerned About? (Multiple responses)

Table 7. While Using an OYBike, Have Any of the Following Ever Been a Problem? (Multiple responses)

stated, the survey respondents may have had a more positive view than those who did not respond.

Thirty-four percent reported that the major reason for trying the system was to experience and test it, suggesting that the system's novelty was one of its key attractions. Another major reason was the desire to use a bicycle occasionally because they do not own one (30\%). Not having to worry about finding secure 
parking for the bicycle and saving time compared to other modes of transport were the other main reasons cited (each by $26 \%$ of respondents).

\section{Usage Evaluation}

Actual bicycle usage was evaluated by analyzing data captured when bicycles are rented and returned. Information was available on a total of 214 trips made by 168 registered users. This is clearly a very small sample and results of this analysis should be interpreted with this in mind. In addition to registered users, trips by 18 sponsored users are also evaluated.

\section{Analysis of Trips and Weather Patterns}

The rollout of the system in late August hampered a quick start-up. Frequency of monthly registrations follows a pattern that is expected from the London climate. Figure 3, which charts new registrations by month, clearly shows that interest in the system was very low during months when weather and lighting conditions are poor.

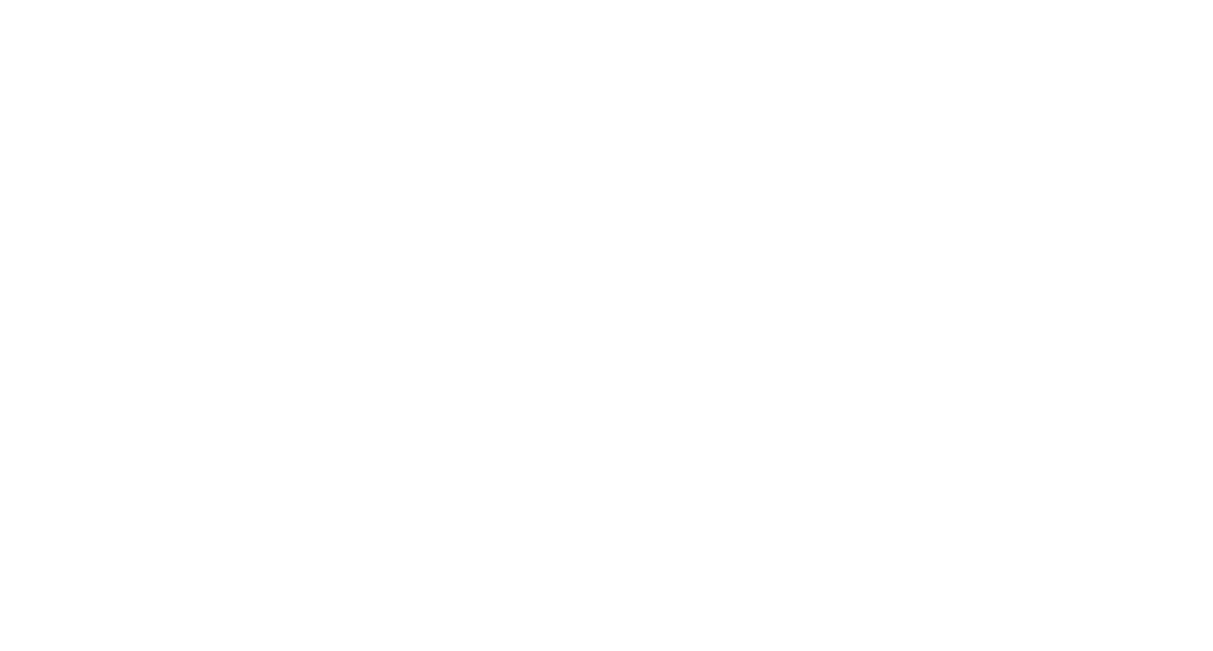

Figure 3. Number of Registrations per Month

Weather conditions appear to play a key role in the usage of OYBike. We explore this relationship in more detail by examining weather data obtained from the UK 
Met Office for the weather station at Heathrow, the nearest weather station to LBHF. Data was obtained for daily weather conditions from August 2004 to August 2005.

We used data on the cumulative percent of days for the maximum temperature, quantity of rainfall, and hours of sunshine. All these factors can be hypothesized to be correlated with bicycle usage. We would expect that higher temperatures would increase bicycle usage, while more rainfall and less sunshine would reduce it.

Figures 4-6 examine the relationship between these weather variables, based on monthly averages and the number of trips taken on OYBike. There is a distinct relationship between average maximum temperatures for each month and total usage. This relationship also holds for the total hours of sunshine in a given month. Rainfall appears to have a negative effect on usage. In particular, usage was relatively high in September 2004 when rainfall was low, compared to October 2004. Temperature has a more important effect in spring and summer months, while rainfall appears to dampen usage.

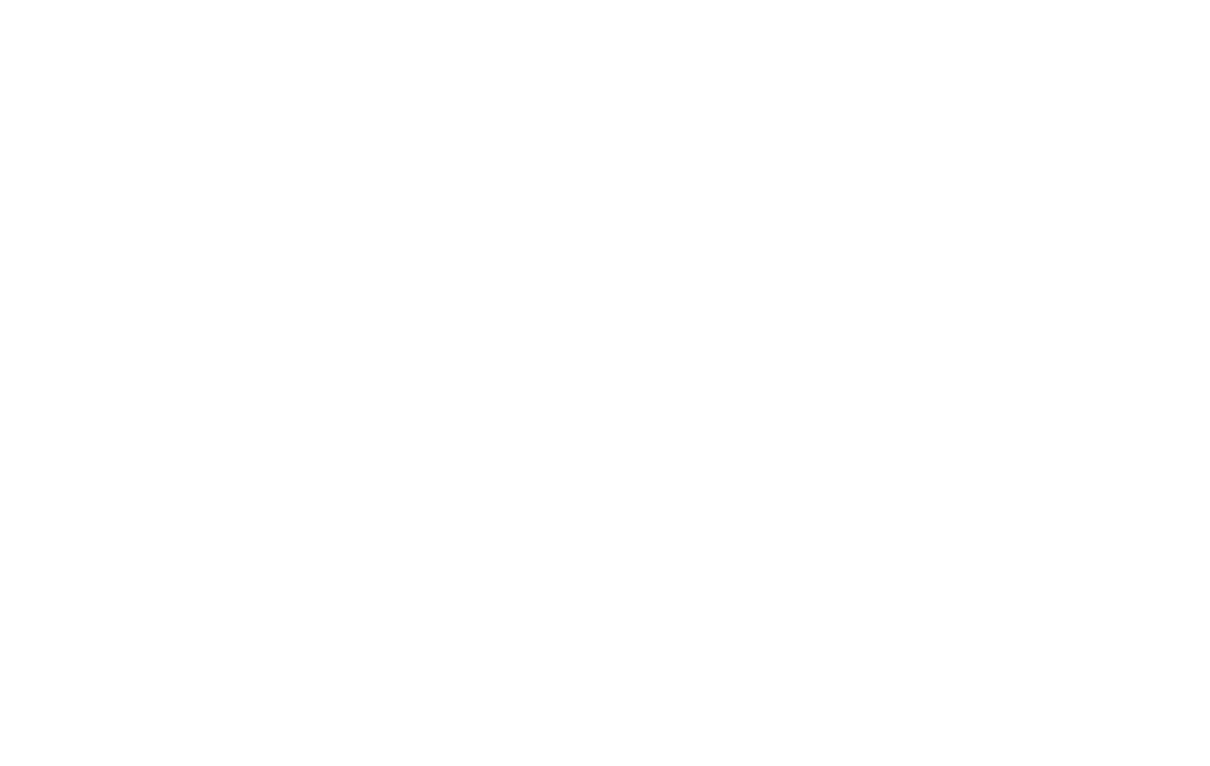

Figure 4. Number of Trips and Average Maximum Temperature 
Figure 5. Number of Trips and Total Monthly Rainfall

Figure 6. Number of Trips and Average Monthly Hours of Sunshine 
The monthly means shown above may hide more interesting effects in the data. Figures 7-9 plot the weather variables against the cumulative number of paid trips taken. Only 10 percent of daily trips were taken on days when the temperature did not exceed $15^{\circ} \mathrm{C}$, and 50 percent of daily trips were taken when the maximum daily temperature exceeded $20^{\circ} \mathrm{C}$, suggesting that higher temperatures do play a major role in increasing usage. The effect of rainfall is more pronounced, as shown in Figure 8. Days with $0 \mathrm{~mm}$ of rainfall account for nearly 70 percent of paid trips. Conversely, a clear pattern emerges of a much smaller percent of total trips on days with significant rainfall.

Figure 9 shows the cumulative percent of trips related to number of hours of sunshine (i.e., a measure of seasonality and cloud cover). This appears to have little effect as the relationship is nearly linear. About 50 percent of cumulative trips were on days with about $0-8$ hours of sunshine, while 50 percent were on days with 8-16 hours of sunshine.

Figure 7. Maximum Daily Temperature vs. Cumulative Percent of Paid Trips 
Figure 8. Daily Rainfall vs. Cumulative Percent of Paid Trips

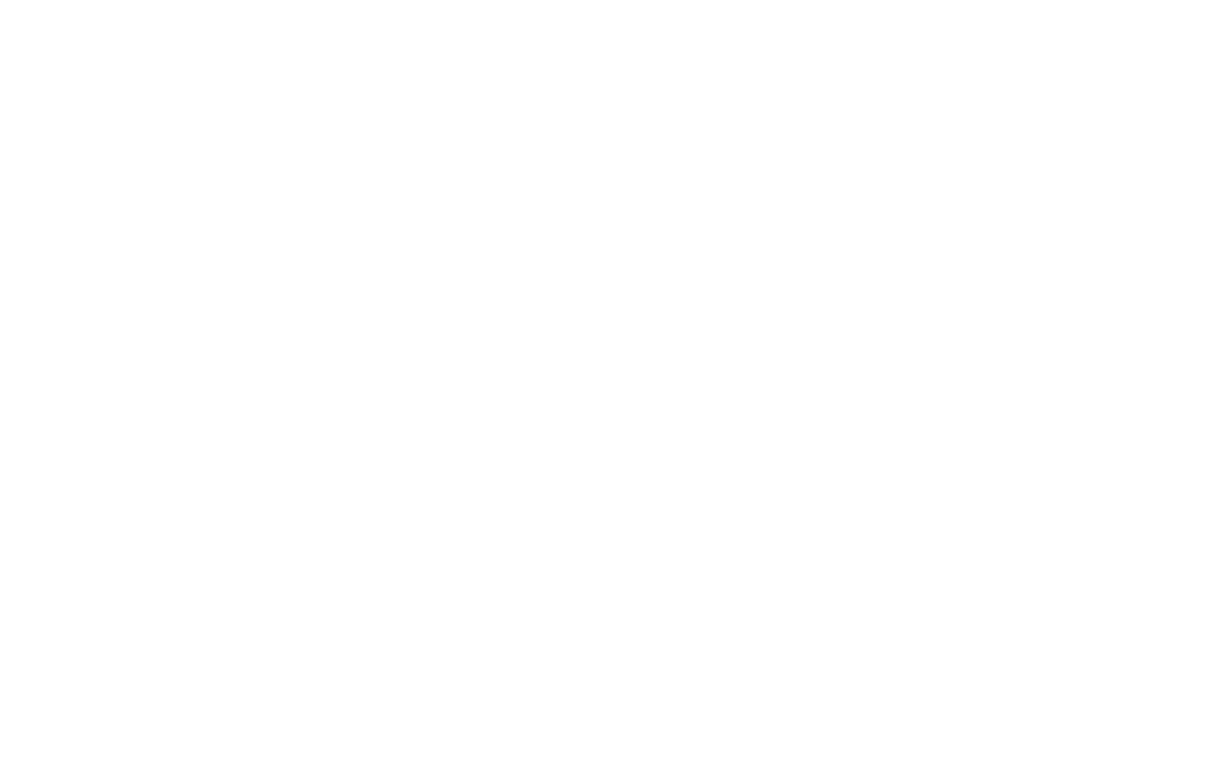

Figure 9. Sunshine Hours per Day vs. Cumulative Percent of Paid Trips 


\section{Analysis of Likely Leisure and Commute Trips}

Analysis of the on-line user survey suggested that recreational and leisure trips were a major market for the bicycles. We examined the usage data to speculate about various patterns in usage that may support this case. The weekly variation indicates that about 51 percent of all usage occurs on weekends, which points to the usage of the system for mainly leisure purposes. Weekend trips also tend to be much longer in duration, which would be consistent with leisure and recreational use of the bicycles rather than use for short utilitarian trips. Figure 10 displays results for number of trips by day of week and the length of the rental.

\section{Figure 10. Number of Trips vs. Day of Week and Length of Hire}

The hourly variation in usage also shows that, on weekends, bicycles are hired at mid-day. A more constant rate of hiring occurs on weekdays, including during morning and afternoon peak travel periods. This suggests that, while weekday trips 
may be for commuting and other utilitarian purposes, weekend trips are likely more focused on leisure and recreation.

This interpretation of the usage pattern can be partially confirmed by linking the user survey with actual bicycle usage. The five users claiming that their primary use was for commuting had a total of 18 trips ( 14 by 1 user, 1 individual took 0 trips). Most of the users claiming their primary purpose was commuting took trips on weekdays. While seven of these were at mid-day (Table 8), those that were in the morning and evening hours were likely commute trips, providing some confirmation that users were reporting their trip purposes accurately.

\section{Table 8. Distribution of Checkout Times for Trips Based on Reported Trip Purpose}

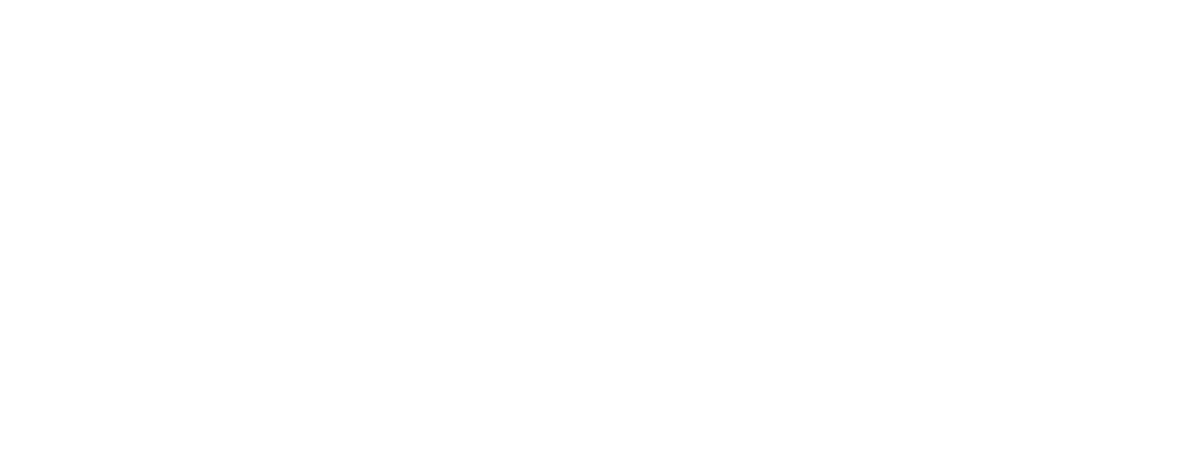

This is further confirmed to some extent by examining the 32 respondents reporting a primary trip purpose of recreational and leisure trips, of which 26 respondents actually took 42 journeys. We see more of a mid-day pattern to their usage as well as much more weekend usage (Table 8). This suggests that the weekend pattern of usage represents recreational and leisure trips.

Further analysis of stated leisure versus commute purposes shows that a primary source of new trips generated by OYBike was for leisure purposes. Those taking trips they would not have otherwise made were trips likely made for leisure purposes (Table 9). Commute trips, on the other hand, seem to have primarily replaced public transport trips. 
Table 9. When You Use OYBike, the Purpose of Your Travel Is Mainly...?

\section{Analysis of Frequency of Usage}

Most registered customers used the service once and almost 26 percent are yet to experience their first ride on the system. Only 8 of a total customer base of 168 have made more than 4 rides, the highest frequency being 14 . Repeat usage is not high, which may suggest some dissatisfaction with the system after initial usage or which may be due to some users trying out the system for its novelty. Those who use the system more than once tend to be weekday users. Weekend users, who generally have only used the bicycle once, are more likely recreational users.

Examining the length of each hire, it is difficult to determine separate effects associated with the frequency of use. Single users and multiple users both have similar patterns of usage in excess of 180 minutes. Single-trip users also show a fairly uniform distribution in shorter rental times as do multiple users.

\section{Analysis of Sponsored Users}

The OYBike system was used by 18 sponsored (nonfee paying) users. Sponsored users include local government employees as well as some members of the public. A total of 107 trips was made by sponsored users. Of these, 71 trips started and terminated at the same location.

Sponsored users clearly have a different pattern of daily usage than paying customers (Figure 11). Usage is greater during the week than on weekends, suggesting that most trips are not for leisure. While the time of day of most sponsored usage does not correspond to peak travel times, the length of trips tend to be much shorter than for fee-paying customers, again suggesting less leisure usage. The length of hire by most sponsored users was less than 15 minutes, although there were a substantial number in excess of 180 minutes (Figure 12). 
Figure 11. Trips by Sponsored Users by Day of the Week

Figure 12. Length of Hire by Sponsored Users 
Use by sponsored users peaked in September 2004 and declined throughout the autumn and winter with only a minor increase during spring and summer. Figure 13 plots this usage along with the maximum daily temperature. It is not known why sponsored usage did not pick up again in the spring and summer of 2005, but this may be partially due to less promotion of the system.

\section{Figure 13. Trips by Sponsored Users and Maximum Daily Temperature}

Examining daily weather conditions and how they affect sponsored users, we see one noticeable difference from the behavior of paid users. More sponsored users took trips on rainy days. About 60 percent of trips are on rainy days as shown in Figure 14 compared to only 30 percent for paid users. This suggests that sponsored-user trips were less likely to be leisure trips, but were perhaps either work related or for commuting, or were simply because of the free availability.

Sponsored users appear to be repeat users more frequently than fee-paying customers. Six sponsored users have used OYBike more than four times, or over onethird of all users (compared to only $5 \%$ of paid users making four or more trips).

Sponsored users used the system overwhelmingly on weekdays (Figure 15), with most bicycles hired during working hours, suggesting that these trips were taken for running errands from work or perhaps for work-related trips. 
Figure 14. Daily Rainfall vs. Cumulative Percent of Total Sponsored Trips

Figure 15. Time of Hire and Weekday vs. Weekend Use by Sponsored Users 


\section{Conclusions}

This evaluation assessed the potential of OYBike as a competitive mode of transport and identified opportunities for making the system work effectively. The analysis is constrained by the small amount of data available; however, there is enough evidence to tentatively support the conclusions that follow.

Analysis of the usage data and the survey data suggest that the primary market is for leisure trips. However, there is also potential for sponsored trips, subsidized by employers, which appear to be more utilitarian. The analysis is based mainly on conjecture regarding trip purposes from the time of day and on which days the trips occurred, with some supporting evidence from the trip purposes stated in the user survey.

The key potential of this particular smart bike system seems to be for leisure trips and recreational purposes. Therefore, finding ways to fully exploit this in terms of marketing and expansion is essential for future growth. Targeted initiatives aimed at recreational users would be beneficial. Also, placing locking stations at key recreational destinations might provide a way to connect public transport stations with recreational destinations and activities. One key issue is that, while London is potentially a very bicycle-accessible city, its road infrastructure, lack of good cycle lanes, and level of traffic are disincentives to widespread use. Despite this, cycle rates in London have increased in recent years (Transport for London 2004b).

Commute and utilitarian trips seem to have been taken primarily by the sponsored user group. One benefit is that these trips are clearly complementary to the leisure market. Sponsored users tended to use the bicycles on weekdays while paid users (who were primarily recreational consumers) used the system on weekends. Sponsored use appeared to be high when the system was originally made available in September 2004. However, while usage declined during winter months, there was no increase in usage by sponsored users to previous levels as the weather warmed. It is unclear why this was so, but it may suggest the need to engage with sponsored users and remind them of the benefits of using the system on a regular basis.

There was a clear pattern of seasonal usage. Both maximum temperature and rainfall totals had an effect on usage. This is not surprising as bicycle usage is a seasonal activity except for the most devoted cyclists. This does, of course, create problems for sustaining the system over many months of nonusage. OYBike reported that nonusage led to more maintenance problems with the gearing system. 
Overall user satisfaction with the system was high. Key impediments to use are the uncertainty of the condition of the bicycles when they are checked out, the difficulty of using the locking system, and the need to use a mobile phone. Cost of using the system was not reported to be an issue. Many cited an interest in testing out the system, but it could not be determined whether this led to repeat usage. Most paid users used the system only once.

Most costumers used the system to replace public transport and walking trips. Although only a minor reduction in reported car trips was found, this is still a beneficial use of potential public resources if some people are diverted from using congested public transport systems. However, most reported usage occurred at nonpeak hours when public transport systems would not be congested. These sorts of effects are, of course, highly dependent on the location of the system. London conditions, such as the level of public transport usage, are fairly unique even in the UK.

Overall, while this system appears to be technically sound, future growth strategies should be geared toward a leisure market. Areas more frequently visited by tourists, with emphasis on sport sites for the London Olympics in 2012, might offer opportunities. Without substantial additional effort at attracting sponsored users, this part of the market will likely remain thin. This conclusion should, however, be taken with caution. First, the data was limited; and second, the specific location in which the pilot was conducted is only representative of a relatively densely populated, but not central, urban area. Potential may be higher within central business districts or conversely, less dense suburban areas (especially for egress from public transport stations). Further analysis of the many systems now being tested would be beneficial (DeMaio and Gifford 2004).

It is unlikely that this type of system could be financially independent of subsidy. The OYBike system was supported by grants from Transport for London and a charitable foundation. Like other systems of this type, OYBike was by no means financially self-supporting. Despite this, these types of systems may be a cheaper means of enhancing mobility than traditional public transport, even with low usage rates.

\section{Acknowledgements}

This research was funded by the SME Innovation Support Programme of the London Development Agency (LDA), part funded through the European Regional 
Development Fund (ERDF), and focused on improving the competitiveness of London's Objective 2 businesses. The OYBike pilot program was partially funded by Transport for London and LBHF.

We would like to thank Martin Frost of the LDA, Simon Franklin of LBHF, and Bernie Hanning and Feroze Rub, the entrepreneurs behind the OYBike system.

The authors have no financial relationships with OYBike or any suppliers of technology to OYBike. In no way should this article be seen as an endorsement of OYBike or the specific technology used by OYBike.

\section{References}

Ball, D., and A. Brooks. 2004. 2001 Census report 2: Ethnic groups in Hammersmith \& Fulham. http://www.lbhf.gov.uk/Images/Part2_pages59-66_tcm21-20275. pdf, 62. Accessed 18 December 2005.

DeMaio, P., and J. Gifford. 2004. Will smart bikes succeed as public transportation in the United States? Journal of Public Transportation 7(2): 1-15.

Greater London Authority. 2001. The mayor's transport strategy. http://www.london.gov.uk/approot/mayor/strategies/transport/trans_strat.jsp. Accessed 18 December 2005.

Transport for London. 2004a. Transport for London annual report. http://www.tfl. gov.uk/tfl/about/report-library/annual-reports/2004/annual_report_2004. shtml. Accessed 18 December 2005.

Transport for London. 2004b. Creating a chain reaction: The London cycling action plan. http://www.tfl.gov.uk/cycles/downloads/reports/cycling-action-plan. pdf. Accessed 18 December 2005.

\section{About the Authors}

ROBERT NOLAND (r.noland@imperial.ac.uk) is a reader in transport and environmental policy and heads the Environment and Policy Research Group within the Centre for Transport Studies at Imperial College London. He received a Ph.D. in energy management and environmental policy from the University of Pennsylvania. Prior to joining Imperial College, Dr. Noland was a policy analyst at the U.S. Environmental Protection Agency and also conducted post-doctoral research in the 
Economics Department at the University of California at Irvine. His research focuses on the impacts of transport policy and behavior on environmental outcomes. This is defined very broadly to include not just air and water quality impacts, but also impacts on safety, climate, health, and other factors associated with overall quality of life.

MUHAMMAD ISHAQUE (moazzam.ishaque@jacobs.com) is a Transport Planner at Jacobs Ltd. He has recently received his Ph.D. from the Centre for Transport Studies, Imperial College London. His research interests include nonmotorized transport and how current traffic control policies affect pedestrians and bicyclists. 